\title{
Short communication: Motivation to walk affects gait attributes
}

\author{
Shabnaz Mokhtarnazif, ${ }^{1,2} \odot$ Anne-Marieke C. Smid, ${ }^{1} \odot$ Daniel M. Weary, ${ }^{1} \odot$ Ahmadreza Mohamadnia, ${ }^{2} \odot$ \\ and Marina A. G. von Keyserlingk ${ }^{1 *}$ (1) \\ ${ }^{1}$ Animal Welfare Program, University of British Columbia, 2357 Mall, Vancouver, BC, Canada, V6T 1 Z4 \\ ${ }^{2}$ Department of Clinical Science, Faculty of Veterinary Medicine, Ferdowsi University of Mashhad, Azadi square, Mashhad, Iran. 9177948974
}

\begin{abstract}
Lameness is a major welfare problem in the dairy industry. Environmental factors, such as flooring surface, as well as cow-level factors, such as udder fill, can influence gait. The aim of the current study was to test whether motivation to walk affects gait attributes and whether this effect differs between lame and sound cows. We trained cows to walk down an alley for a food reward and assessed walking speed, stride length, head bob, and back arch of cows previously identified as either lame $(\mathrm{n}=7)$ or sound $(\mathrm{n}=10)$. Cows were assessed when they walked toward a food reward and toward no reward. Cows walked faster and had longer stride length and less variation in head bob when approaching the reward; these effects were similar in both sound and lame cows. We concluded that motivation to walk affects several gait attributes of dairy cows.
\end{abstract}

Key words: animal welfare, locomotion, behavior, quantitative gait assessment

\section{Short Communication}

Lameness is a major problem in the dairy industry (Barker et al., 2010; Solano et al., 2015), with an average herd-level prevalence of approximately 25\% (Cook et al., 2016). Lameness causes pain (O'Callaghan et al., 2003; Laven, 2018) and results in economic losses (Ettema and Østergaard, 2006; Huxley, 2013). Reliable scoring systems are required to better identify, treat, and prevent lameness.

Various locomotion-scoring systems exist; each uses one or several measures related to body posture (e.g., back arch, head bob) and locomotion (e.g., tracking up, reluctance to bear weight; Manson and Leaver, 1988; Sprecher et al., 1997; Flower and Weary, 2006). Environmental factors such as walking surface (Fjeldaas et al., 2011) can influence these measures, potentially

Received December 14, 2019.

Accepted May 12, 2020.

*Corresponding author: nina@mail.ubc.ca leading to misclassification (Van Nuffel et al., 2016). For example, cows walking on slatted versus solid concrete flooring were on average assigned a worse locomotion score (Fjeldaas et al., 2011), cows had shorter strides and worse tracking up when walking on slatted concrete compared with compressed sand (Telezhenko and Bergsten, 2005), and cows walked faster and with longer strides on pasture compared with asphalt (Alsaaod et al., 2017). Weather conditions can also affect gait; for instance, in rainy and windy weather cows walked slower and with their head down and used shorter and more asymmetric strides (Van Nuffel et al., 2016).

Cow-level factors can also affect gait. For example, Blackie et al. (2011) reported that after calving, cows walked with increased arched back and stiffness, possibly due to pain in the hindquarters. Cows also walked faster toward a feed reward than toward an aversive treatment (Pajor et al., 2000). Flower et al. (2006) suggested that the higher and longer strides displayed by cows after milking may be caused by their motivation to access fresh feed after milking. However, no work has directly assessed the effect of the motivation to walk on gait attributes. The aim of this study was to investigate the effect of motivation to walk on cow gait and to determine whether this effect differed between sound and lame cows. We hypothesized that when cows were more motivated to walk, they would walk faster, use longer strides, and show less back arch and head bob.

This experiment took place in November and December 2017 at the University of British Columbia's Dairy Education and Research Centre in Agassiz, British Columbia, Canada. The University of British Columbia's Animal Care Committee approved the experiment and all procedures (Protocol A15-0082).

During the training and testing periods (see next sections), experimental cows were housed in a freestall pen together with nonexperimental animals at $100 \%$ stocking density. Thirty-six freestalls $(1.2 \times 2.4 \mathrm{~m})$ were filled with 30 to $40 \mathrm{~cm}$ of washed river sand that was raked twice daily and were replenished with additional sand every other week. The feed barrier consisted of 35 headlocks and 1 open feeding space, each providing $60 \mathrm{~cm}$ of access to the feed. The concrete alleys were 
scraped automatically 6 times/d and crossover alleys were cleaned manually twice daily when cows were gone for milking.

Cows were fed a TMR formulated following the National Research Council guidelines (NRC, 2001) to meet or exceed the requirements of a $658-\mathrm{kg}$ Holstein producing $39 \mathrm{~kg}$ of milk/d. The TMR consisted of $30 \%$ corn silage, $39 \%$ concentrate mash, $20 \%$ alfalfa hay, $6 \%$ grass haylage, $3.5 \%$ low concentrate mash, $1.5 \%$ grass hay, and $0.7 \%$ wheat straw on a DM basis and was available ad libitum. Fresh feed was delivered between 0530 and $0600 \mathrm{~h}$ and between 1530 and $1600 \mathrm{~h}$; leftover feed was removed at approximately $0530 \mathrm{~h}$. Animals were milked in a double-12 parallel milking parlor between 0600 and $0700 \mathrm{~h}$ and between 1500 and $1600 \mathrm{~h}$.

Twenty-six pregnant Holstein cows were randomly selected from the main herd (average \pm SD parity of sound cows $=2.7 \pm 1.1$ and lame cows $=3.1 \pm 1.3$; average \pm SD DIM of sound cows $=216 \pm 85$ and lame cows $=249 \pm 86$; average \pm SD BCS of sound cows $=3.6 \pm 0.7$ and lame cows $=3.2 \pm 0.5$ ). Cows were gait scored live using the procedure described by Flower and Weary (2006) and categorized as sound (i.e., score $<3$ ) or lame (i.e., score 3 or 4 ). For animal welfare reasons, we did not include any cows with a gait score of 5 . Cows were selected, trained, and tested in 2 groups, both including a mixture of lame and sound cows (group $1, \mathrm{n}=15$ and group $2, \mathrm{n}=11$ ). The 2 groups were tested $14 \mathrm{~d}$ apart.

During training cows were made familiar with the 2 treatments. Cows were individually taken out of their home pen between 1100 and $1400 \mathrm{~h}$ and gently encouraged to walk to the end of an alley $(20 \times 3 \mathrm{~m} ; 1.1 \mathrm{~m}$ wide) adjacent to their home pen. At the end of the alley, a red bucket filled with grain (Standard Distiller's grain mash, Hi-Pro, Chilliwack, BC, Canada; consisting of $87.8 \% \mathrm{DM}, 21.0 \% \mathrm{CP}, 4.4 \%$ crude fat, $7.8 \% \mathrm{ADF}$, $19.6 \% \mathrm{NDF}, 26.4 \%$ starch, and $2.64 \mathrm{Mcal} / \mathrm{kg} \mathrm{ME}$ on a DM basis) was provided as the positive treatment; the lack of a bucket was used as control treatment. Each training session consisted of 2 laps of each treatment for each cow. The first treatment for each cow was randomized on the first day of training and then reversed daily. Training sessions were video recorded (Sony Handycam HDR-CX560V, San Diego, CA) and recordings were used to measure the walking speed of each lap (details provided below). Cows were considered trained when for 3 consecutive training days (1) they had a higher average walking speed during the positive than the control treatment, (2) the speed in the positive laps was never lower than the average speed in the control laps $(+2 \mathrm{SD})$ and, 3) the speed in the control laps did not exceed the average speed in the positive laps $(-2 \mathrm{SD})$. Of the initial 26 cows, 8 cows from group 1 and 9 cows from group 2 met the training criteria and entered the test phase of the experiment. Of these 17 test animals, 10 were categorized as sound and 7 as lame.

In the test phase, each cow was tested for 2 to 5 consecutive days using the same procedure as described in the training phase. If a cow failed to walk in a straight line, stopped, stumbled, slipped, ran, defecated, or urinated, the lap was considered unsuccessful. All cows had to complete 1 successful lap per treatment during 2 test sessions; each cow was given a maximum of 2 attempts per treatment during each session. All cows were video recorded from their left side using a video camera (Sony Handycam HDR-CX560V) placed at a distance of $3.5 \mathrm{~m}$ perpendicular to the walking alley. If a cow completed 2 laps per treatment in one session, the best lap of the treatment (i.e., the lap in which the cow showed least evidence of disturbance and walked faster) was selected and used for the analysis.

Cows were gait scored live for initial selection, and then rescored from video to provide a final gait score reported below. A trained observer, blind to the treatment, assigned gait score from video recordings following Flower and Weary (2006). Four gait scores were obtained per cow (i.e., 2 test days and 2 treatments). All sound cows had gait score 2. Of the lame cows, 6 cows had gait score 3 and 1 cow had gait score 4 . For all cows but 1 , the gait score remained the same in all 4 laps. For the 1 cow that was assigned 2 different gait scores, the median score was assigned. Interobserver reliability was scored by comparing 20 videos scored independently by the main observer and a second trained observer. Intraobserver reliability was scored after every 80 videos by comparing 10 to 15 videos scored twice by the main observer. Cohen's kappa was 0.77 for interobserver reliability and was always $>0.60$ for intraobserver reliability.

To assess walking speed, the time to walk between 2 poles spaced $7.35 \mathrm{~m}$ apart was recorded. To measure stride length, a snapshot was taken using a VLC media player (2.2.6 Umbrella, VideoLAN, Paris, France) of each moment that a hoof landed on the floor, after which the placement of each hoof landing was marked using Adobe Photoshop CS6 (Version 13.0 x64, Adobe Systems, San Jose, CA; see Appendix Figure A1). To measure stride length, the horizontal distance between each consecutive hoof strike of the same hoof (Flower et al., 2006) was measured using ImageJ (ImageJ $1.51 \mathrm{~s}$, Wayne Rasband, National Institutes of Health, Bethesda, MD).

A 1.9-m subsection of the alleyway was fitted with a wooden backdrop (1.2 m high); this provided a solid surface to facilitate the measurements of the back arch and head bob. The back arch area was calculated using the procedure described by Stojkov et al. (2015) 
and defined as the space between 2 lines that connect the thoracic vertebra with the longest dorsal spine (A) and the lumbo-sacral junction (B; see Appendix Figure A2). Both points were marked using a livestock spray (Tell Tail animal marker, GEA, Mt Maunganui, New Zealand) on the cows after the last training session to facilitate this measurement. The base of the semicircle (i.e., the shortest distance between A and B) was used to control for the difference in body size between cows. Using VLC media player, 4 screenshots were taken per lap, 1 for each time the cow landed 1 of her hooves in front of the camera. ImageJ was used to calculate the total surface of the back arch area of each screenshot.

To measure the head bob, a snapshot was taken each time the lower jaw of the cow was at its highest position and the time it was at its lowest position using VLC media player. Using the same procedure as for stride length, the head positions were marked in one photo using Adobe Photoshop CS6. Thereafter, using ImageJ, the difference in vertical distance between each adjacent head position was measured (see Appendix Figure A3).

Reliability was assessed by calculating the correlation of 10 measures, taken independently by 2 trained observers. Interobserver reliability (as assessed via the $\mathrm{R}^{2}$ ) for walking speed, stride length, back arch, and head bob was $1.0,0.96,0.91$, and 0.91 , respectively. To calibrate measurements taken with ImageJ, a square $(10 \times 10 \mathrm{~cm})$ drawing was placed in front of the camera at the beginning of each test day. We then correlated the real-life measurement with the number of pixels read by Image J of this picture. To check whether this calibration was successful, we then selected the whole square and checked whether the pixel count as provided by ImageJ corresponded to $100 \mathrm{~cm}^{2}$. If successful, this setting was then used for all the measurements taken that day.

The average stride length per leg was calculated and then used to calculate the average stride length of all legs. For 3 cows, the back arch could not be measured for 1 leg because one mark was not clearly visible in the video at the time that leg landed; for these cows, back arch was calculated as the average of the 3 remaining legs. The standard deviation of all head positions was calculated per lap; the head bob of 4 cows could not be measured during one lap due to a head position that was difficult to measure.

Data were analyzed using SAS (version 9.4, SAS Institute Inc., Cary, NC), specifying cow as the experimental unit. Sample size was calculated using an online sample size calculator for paired data (Dhand and Khatkar, 2014). Based on data on walking speed and stride length of cows without sole ulcers from the study by Flower et al. (2006), 7 cows were needed based on stride length measurements (to detect a mean \pm SD difference of $12.8 \pm 8.7 \mathrm{~cm}$ ), and 6 cows were needed based on walking speed measurements (to detect a mean \pm SD difference of $0.19 \pm 0.1 \mathrm{~m} / \mathrm{s}$ ) with a power of 0.8 at an $\alpha$ level of 0.05 . The measures obtained for each cow (except for gait score) on both days for each treatment were averaged and used in the final analysis. Data were scrutinized using PROC UNIVARIATE. All variables except for head bob were normally distributed. The latter variable was log-transformed to normalize. A mixed model was used with treatment, lameness category (i.e., sound or lame), and treatment $\times$ lameness category as fixed effects and cow as random effect. The correlation between all 4 variables (speed, stride length, back arch, and head bob) was investigated using PROC CORR. Walking speed and stride length were highly correlated $(\mathrm{r}>0.8)$. However, as our aim was to describe each gait attribute separately, we analyzed all variables. A weak correlation (i.e., all $\mathrm{r}<0.54$ ) was found between the other variables. Significance was accepted when $P<$ 0.05 and a trend was considered when $P<0.10$.

As expected, cows walked faster when approaching the food reward compared with the control condition $\left(F_{1,15}=60.33, P<0.001\right)$. In addition, lame cows walked slower than sound cows $\left(F_{1,15}=10.29, P=\right.$ 0.0059; Figure 1A). Cows approaching the reward also walked with a longer stride length $\left(F_{1,15}=53.86, P<\right.$ 0.001 ), and lame cows had shorter stride lengths than sound cows $\left(F_{1,15}=8.84, P=0.0095\right.$; Figure $\left.1 \mathrm{~B}\right)$. Cows tended to show decreased back arch when approaching the reward $\left(F_{1,15}=3.20, P=0.0938\right)$, and lame cows showed more back arch than sound cows $\left(F_{1,15}=7.26\right.$, $P=0.0166$; Figure 1C). A lower standard deviation of the head location (i.e., lower head bob) was recorded in the food reward treatment $\left(F_{1,15}=4.63, P=0.0480\right)$, and lame cows also showed more head bob than sound cows $\left(F_{1,15}=4.82, P=0.0444\right.$; Figure $\left.1 D\right)$. No interactions were significant.

When cows approached a grain-filled bucket, they walked faster and with longer strides. Pajor et al. (2000) and Van Nuffel et al. (2016) reported that cow motivation to walk toward feed or away from an aversive stimulus affected variables such as the landing and lifting time of the cow's legs, behaviors that collectively resulted in a higher walking speed.

Flower et al. (2006) reported that cows walked with longer and higher strides after milking and suggested that this change in gait might be either due to reduced udder distension after milking or because of the cows' motivation to return to their home pen to access fresh feed. Feed motivation has been shown to influence walking speed in other animals including pigs (Souza da Silva et al., 2012), poultry (Bokkers and Koene, 2004), 
sheep (Verbeek et al., 2011), and beetles (McIntyre and Wiens, 1999). These results indicate that motivation to walk affects gait.

Lameness is associated with walking speed (Zillner et al., 2018), potentially because lame cows increase their landing and lifting time as they try to place their affected hoof more carefully on the ground (Van De Gucht et al., 2017). Lame cows generally have shorter strides, resulting in more steps to pass through the same distance (Beer et al., 2016). In our study, lame cows walked slower and with shorter strides than sound cows. However, lame cows also increased their walking speed and stride length in the positive treatment, indicating that motivation to walk could potentially mask lameness to some degree.

Back arch (i.e., the posture of the cows' thoracic and lumbar vertebrae) is a key attribute used to detect lameness (Sprecher et al., 1997; Flower et al., 2005; García-Muñoz et al., 2016). In our study, cows motivated to walk tended to show less back arch, potentially because of a more upright head position in anticipation of the food reward. Back arch was larger in lame cows.

Head bob is a result of unequal weight shifting between legs during walking (Nordlund et al., 2004; Van Nuffel et al., 2015). Head movement is described in horses as an increase in the vertical head movement when the affected leg lands (Keegan et al., 2001). When cows were more motivated to walk, the standard deviation of the head location was lower. This steadier head carriage may be related to the curvature of the spine, as a correlation between head position and back posture has been reported for horses (Lesimple et al., 2016: Sénèque et al., 2018), although in our study the correlation between the head bob and back arch was low (i.e., $r<0.2$ ).

We found that motivation to walk affected multiple gait attributes; cows walked faster, with longer stride lengths, and with less head bob when they were more motivated to walk (i.e., toward a food reward). These results illustrate the value of assessing more subtle
A

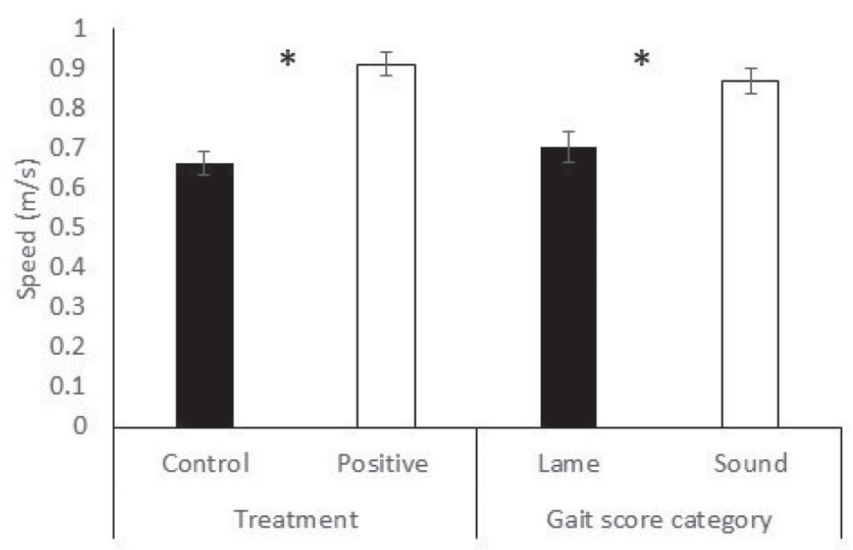

$\mathrm{C}$

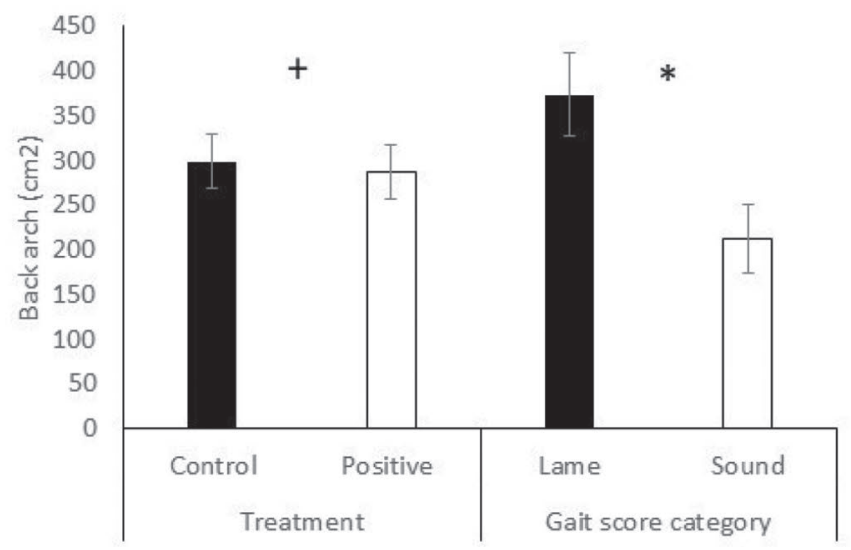

B

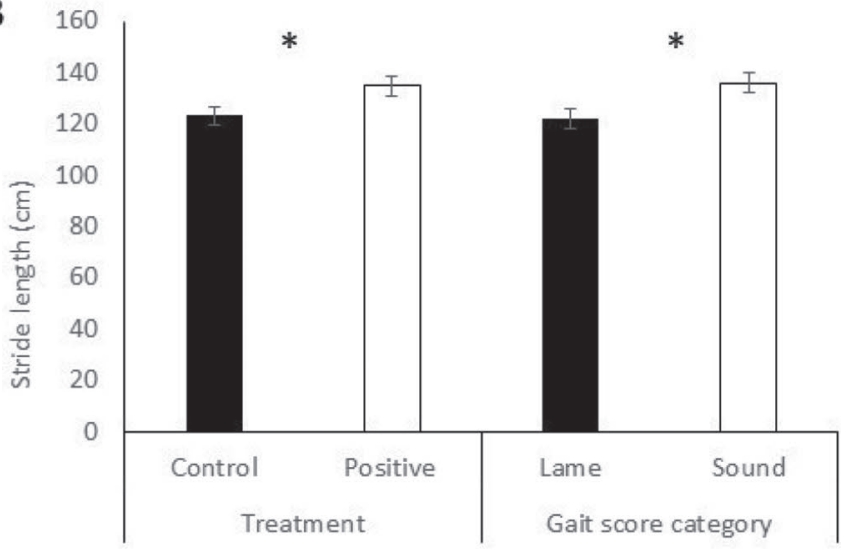

D

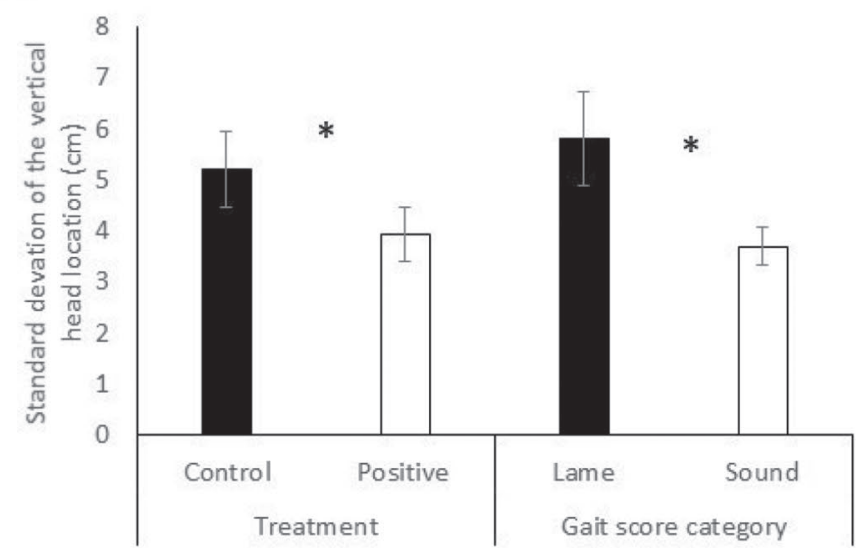

Figure 1. (A) Mean ( \pm SE) walking speed, (B) stride length, (C) back arch area, and (D) standard deviation of the head position during the positive and control treatment and in lame $(\mathrm{n}=7)$ and sound $(\mathrm{n}=10)$ cows. ${ }^{*}$ Indicates significance $(P<0.05) ;+$ indicates a trend $(P<0.1)$. 
changes in cow gait. We did not find an effect of motivation on overall gait score. Given that we scored gait in whole units, it is possible that our measurement method was not sufficiently sensitive to detect an effect. We encourage further work using more sensitive scoring methods.

\section{ACKNOWLEDGMENTS}

We thank the staff of the University of British Columbia Dairy Education and Research Centre for their help with the experiment. We are grateful to Marzie Faezi (Damasa, Herd Health Research and Extension Group, Mashhad, Iran) for helping us obtain interobserver reliability values for the different gait attributes, and to Bruna Ruberti (Animal Welfare Program, Vancouver, BC, Canada) for gait scoring the cows from video recordings. M. A. G. von Keyserlingk and D. M. Weary are supported by Canada's Natural Sciences and Engineering Research Council via the Industrial Research Chair Program with industry contributions from Alberta Milk (Edmonton, AB, Canada), British Columbia Dairy Association (Burnaby, BC, Canada), Boehringer Ingelheim (Burlington, ON, Canada), BC Cattle Industry Development Fund (Kamloops, BC, Canada), Dairy Farmers of Canada (Ottawa, ON, Canada), Dairy Farmers of Manitoba (Winnipeg, MB, Canada), Intervet Canada Corporation (Kirkland, QC, Canada), Saputo (Montreal, QC, Canada), SaskMilk (Regina, SK, Canada), Semex Alliance (Guelph, ON, Canada) and Lactanet (Sainte-Anne-de-Bellevue, QC, Canada). The authors confirm that there are no known conflicts of interest associated with this publication.

\section{REFERENCES}

Alsaaod, M., S. Huber, G. Beer, P. Kohler, G. Schüpbach-Regula, and A. Steiner. 2017. Locomotion characteristics of dairy cows walking on pasture and the effect of artificial flooring systems on locomotion comfort. J. Dairy Sci. 100:8330-8337. https://doi.org/ $10.3168 /$ jds.2017-12760.

Barker, Z. E., K. A. Leach, H. R. Whay, N. J. Bell, and D. C. J. Main. 2010. Assessment of lameness prevalence and associated risk factors in dairy herds in England and Wales. J. Dairy Sci. 93:932-941. https://doi.org/10.3168/jds.2009-2309.

Beer, G., M. Alsaaod, A. Starke, G. Schuepbach-Regula, H. Müller, P. Kohler, and A. Steiner. 2016. Use of extended characteristics of locomotion and feeding behavior for automated identification of lame dairy cows. PLoS One 11:e0155796. https://doi.org/10.1371/ journal.pone. 0155796 .

Blackie, N., E. Bleach, J. Amory, and J. Scaife. 2011. Impact of lameness on gait characteristics and lying behaviour of zero grazed dairy cattle in early lactation. Appl. Anim. Behav. Sci. 129:67-73. https://doi.org/10.1016/j.applanim.2010.10.006.

Bokkers, E. A. M., and P. Koene. 2004. Motivation and ability to walk for a food reward in fast- and slow-growing broilers to 12 weeks of age. Behav. Processes 67:121-130. https://doi.org/10.1016/j .beproc.2004.03.015.

Cook, N. B., J. P. Hess, M. R. Foy, T. B. Bennett, and R. L. Brotzman. 2016. Management characteristics, lameness, and body injuries of dairy cattle housed in high-performance dairy herds in Wisconsin. J. Dairy Sci. 99:5879-5891. https://doi.org/10.3168/jds.2016 -10956 .

Dhand, N. K., and M. S. Khatkar. 2014. Statulator: An Online Statistical Calculator. Sample size calculator for comparing two paired means. Accessed May 7, 2020. http://statulator.com/SampleSize/ ss2PM.html.

Ettema, J. F., and S. Østergaard. 2006. Economic decision making on prevention and control of clinical lameness in Danish dairy herds. Livest. Sci. 102:92-106. https://doi.org/10.1016/j.livprodsci.2005 .11 .021 .

Fjeldaas, T., Å. M. Sogstad, and O. Østerås. 2011. Locomotion and claw disorders in Norwegian dairy cows housed in freestalls with slatted concrete, solid concrete, or solid rubber flooring in the alleys. J. Dairy Sci. 94:1243-1255. https://doi.org/10.3168/jds.2010 $-3173$.

Flower, F. C., D. J. Sanderson, and D. M. Weary. 2005. Hoof pathologies influence kinematic measures of dairy cow gait. J. Dairy Sci 88:3166-3173. https://doi.org/10.3168/jds.S0022-0302(05)73000 $-9$.

Flower, F. C., D. J. Sanderson, and D. M. Weary. 2006. Effects of milking on dairy cow gait. J. Dairy Sci. 89:2084-2089. https://doi .org/10.3168/jds.S0022-0302(06)72278-0.

Flower, F. C., and D. M. Weary. 2006. Effect of hoof pathologies on subjective assessments of dairy cow gait. J. Dairy Sci. 89:139-146. https://doi.org/10.3168/jds.S0022-0302(06)72077-X.

García-Muñoz, A., G. Vidal, N. Singh, and N. Silva-del-Río. 2016. Evaluation of two methodologies for lameness detection in dairy cows based on postural and gait abnormalities observed during milking and while restrained at headlock stanchions. Prev. Vet. Med. 128:33-40. https://doi.org/10.1016/j.prevetmed.2016.04.005.

Huxley, J. N. 2013. Impact of lameness and claw lesions in cows on health and production. Livest. Sci. 156:64-70. https://doi.org/10 .1016/j.livsci.2013.06.012.

Keegan, K. G., P. F. Pai, D. A. Wilson, and B. K. Smith. 2001. Signal decomposition method of evaluating head movement to measure induced forelimb lameness in horses trotting on a treadmill. Equine Vet. J. 33:446-451. https://doi.org/10.2746/042516401776254781.

Laven, R. 2018. Managing pain in lame cattle. Livestock (Lond) 23:161-167. https://doi.org/10.12968/live.2018.23.4.161.

Lesimple, C., C. Fureix, L. Aubé, and M. Hausberger. 2016. Detecting and measuring back disorders in nonverbal individuals: The example of domestic horses. Anim. Behav. Cogn. 3:159-179. https: //doi.org/10.12966/abc.05.08.2016.

Manson, F. J., and J. D. Leaver. 1988. The influence of concentrate amount on locomotion and clinical lameness in dairy cattle. Anim. Sci. 47:185-190. https://doi.org/10.1017/S0003356100003251.

McIntyre, N. E., and J. A. Wiens. 1999. Interactions between landscape structure and animal behavior: The roles of heterogeneously distributed resources and food deprivation on movement patterns. Landsc. Ecol. 14:437-447. https://doi.org/10.1023/A: 1008074407036

Nordlund, K. V., N. B. Cook, and G. R. Oetzel. 2004. Investigation strategies for laminitis problem herds. J. Dairy Sci. 87(Suppl.):E27E35. https://doi.org/10.3168/jds.S0022-0302(04)70058-2.

NRC (National Research Council). 2001. Nutrient Requirements of Dairy Cattle. 7th rev. ed. The National Academies Press, Washington, DC.

O'Callaghan, K. A., P. J. Cripps, D. Y. Downham, and R. D. Murray. 2003. Subjective and objective assessment of pain and discomfort due to lameness in dairy cattle. Anim. Welf. 12:605-610.

Pajor, E. A., J. Rushen, and A. M. B. de Passillé. 2000. Aversion learning techniques to evaluate dairy cattle handling practices. Appl. Anim. Behav. Sci. 69:89-102. https://doi.org/10.1016/S0168 $-1591(00) 00119-2$.

Sénèque, E., S. Morisset, C. Lesimple, and M. Hausberger. 2018. Testing optimal methods to compare horse postures using geometric morphometrics. PLoS One 13:e0204208. https://doi.org/10.1371/ journal.pone.0204208.

Solano, L., H. W. Barkema, E. A. Pajor, S. Mason, S. J. LeBlanc, J. C. Zaffino Heyerhoff, C. G. R. Nash, D. B. Haley, E. Vasseur, D. 
Pellerin, J. Rushen, A. M. de Passillé, and K. Orsel. 2015. Prevalence of lameness and associated risk factors in Canadian HolsteinFriesian cows housed in freestall barns. J. Dairy Sci. 98:6978-6991. https://doi.org/10.3168/jds.2015-9652.

Souza da Silva, C., J. J. G. C. van den Borne, W. J. J. Gerrits, B. Kemp, and J. E. Bolhuis. 2012. Effects of dietary fibers with different physicochemical properties on feeding motivation in adult female pigs. Physiol. Behav. 107:218-230. https://doi.org/10.1016/j .physbeh.2012.07.001.

Sprecher, D. J., D. E. Hostetler, and J. B. Kaneene. 1997. A lameness scoring system that uses posture and gait to predict dairy cattle reproductive performance. Theriogenology 47:1179-1187. https:// doi.org/10.1016/S0093-691X(97)00098-8.

Stojkov, J., M. A. G. von Keyserlingk, J. N. Marchant-Forde, and D. M. Weary. 2015. Assessment of visceral pain associated with metritis in dairy cows. J. Dairy Sci. 98:5352-5361. https://doi.org/10 $.3168 /$ jds.2014-9296.

Telezhenko, E., and C. Bergsten. 2005. Influence of floor type on the locomotion of dairy cows. Appl. Anim. Behav. Sci. 93:183-197. https://doi.org/10.1016/j.applanim.2004.11.021.

Van De Gucht, T., W. Saeys, S. Van Weyenberg, L. Lauwers, K. Mertens, L. Vandaele, J. Vangeyte, and A. Van Nuffel. 2017. Automatically measured variables related to tenderness of hoof placement and weight distribution are valuable indicators for lameness in dairy cows. Appl. Anim. Behav. Sci. 189:13-22. https://doi.org/ 10.1016/j.applanim.2017.01.011.

Van Nuffel, A., T. Van De Gucht, W. Saeys, B. Sonck, G. Opsomer, J. Vangeyte, K. C. Mertens, B. De Ketelaere, and S. Van Weyenberg.
2016. Environmental and cow-related factors affect cow locomotion and can cause misclassification in lameness detection systems. Animal 10:1533-1541. https://doi.org/10.1017/S175173111500244X.

Van Nuffel, A., I. Zwertvaegher, L. Pluym, S. Van Weyenberg, V. M. Thorup, M. Pastell, B. Sonck, and W. Saeys. 2015. Lameness detection in dairy cows: Part 1 . How to distinguish between non-lame and lame cows based on differences in locomotion or behavior. Animals (Basel) 5:838-860. https://doi.org/10.3390/ani5030387.

Verbeek, E., J. R. Waas, L. McLeay, and L. R. Matthews. 2011. Measurement of feeding motivation in sheep and the effects of food restriction. Appl. Anim. Behav. Sci. 132:121-130. https://doi.org/ 10.1016/j.applanim.2011.03.014.

Zillner, J. C., N. Tücking, S. Plattes, T. Heggemann, and W. Büscher. 2018. Using walking speed for lameness detection in lactating dairy cows. Livest. Sci. 218:119-123. https://doi.org/10.1016/j.livsci .2018.10.005.

\section{ORCIDS}

Shabnaz Mokhtarnazif ( https://orcid.org/0000-0001-5013-5809 Anne-Marieke C. Smid ๑ https://orcid.org/0000-0001-9810-4032 Daniel M. Weary @ https://orcid.org/0000-0002-0917-3982

Ahmadreza Mohamadnia @ https://orcid.org/0000-0003-1459-3989 Marina A. G. von Keyserlingk (0) https://orcid.org/0000-0002-1427 $-3152$

\section{APPENDIX}

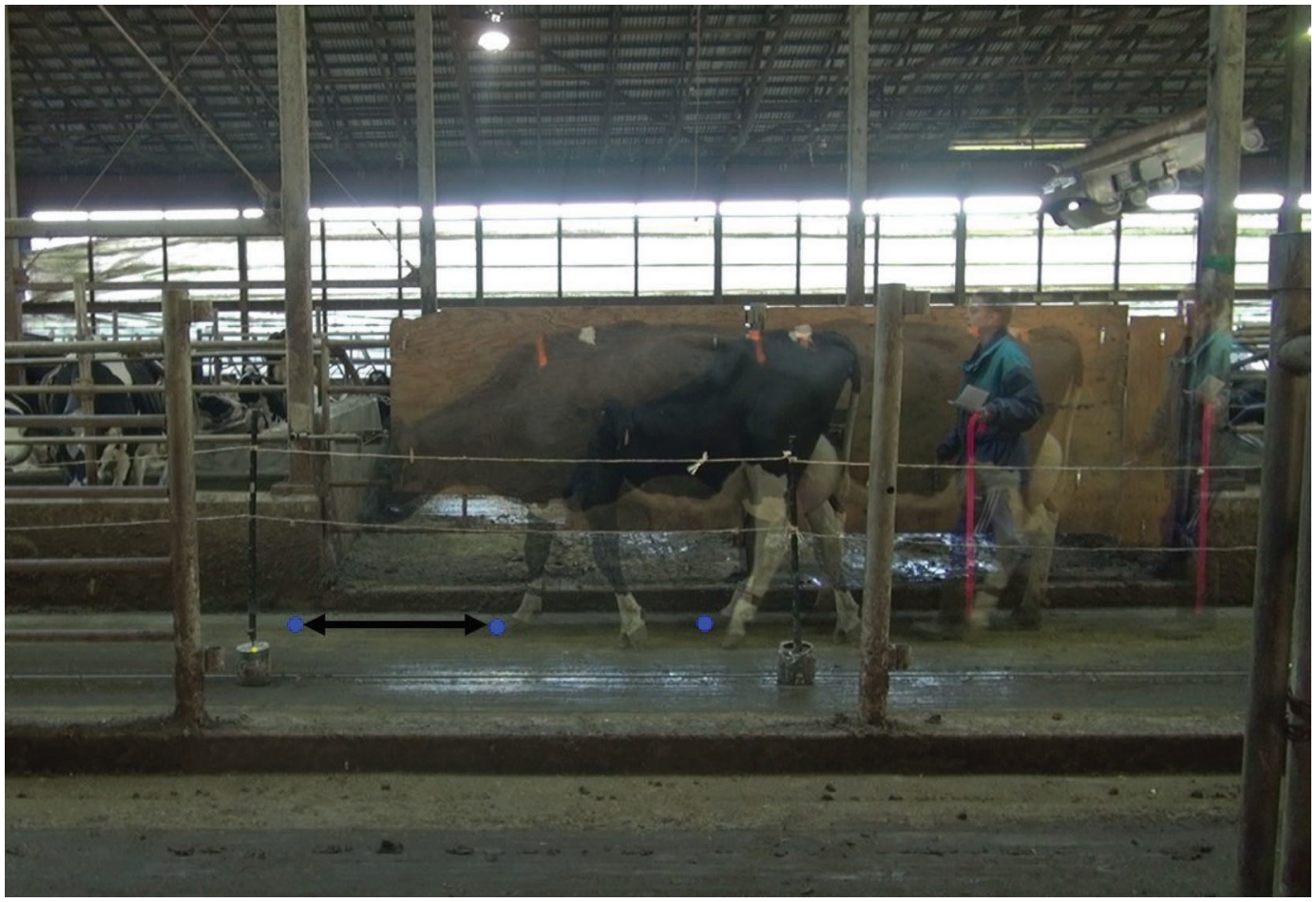

Figure A1. The landing places of one hoof (i.e., right front leg in this example) were marked in the same photo using Photoshop (Adobe Photoshop CS6, Adobe Systems, San Jose, CA); the arrow indicates the horizontal distance between 2 successive strides of the same leg. 


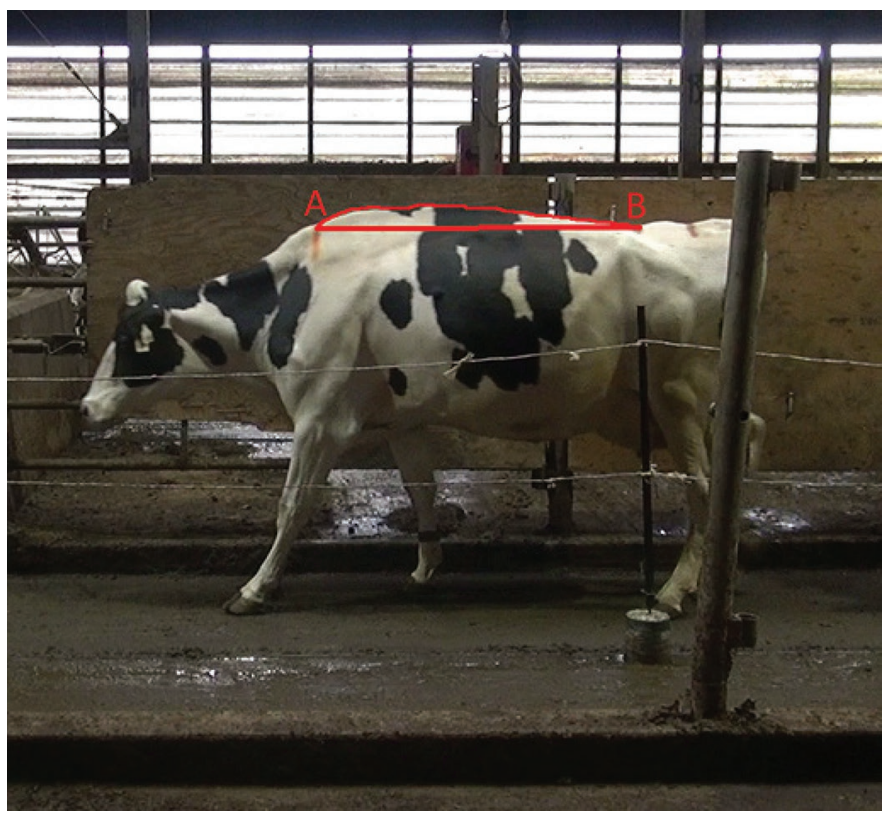

Figure A2. Two lines were drawn connecting the thoracic vertebra (A) and the lumbo-sacral junction (B), one tracing the curvature of the spine and the second a straight line connecting the two points; total back arch area was calculated as the area defined by these two lines.

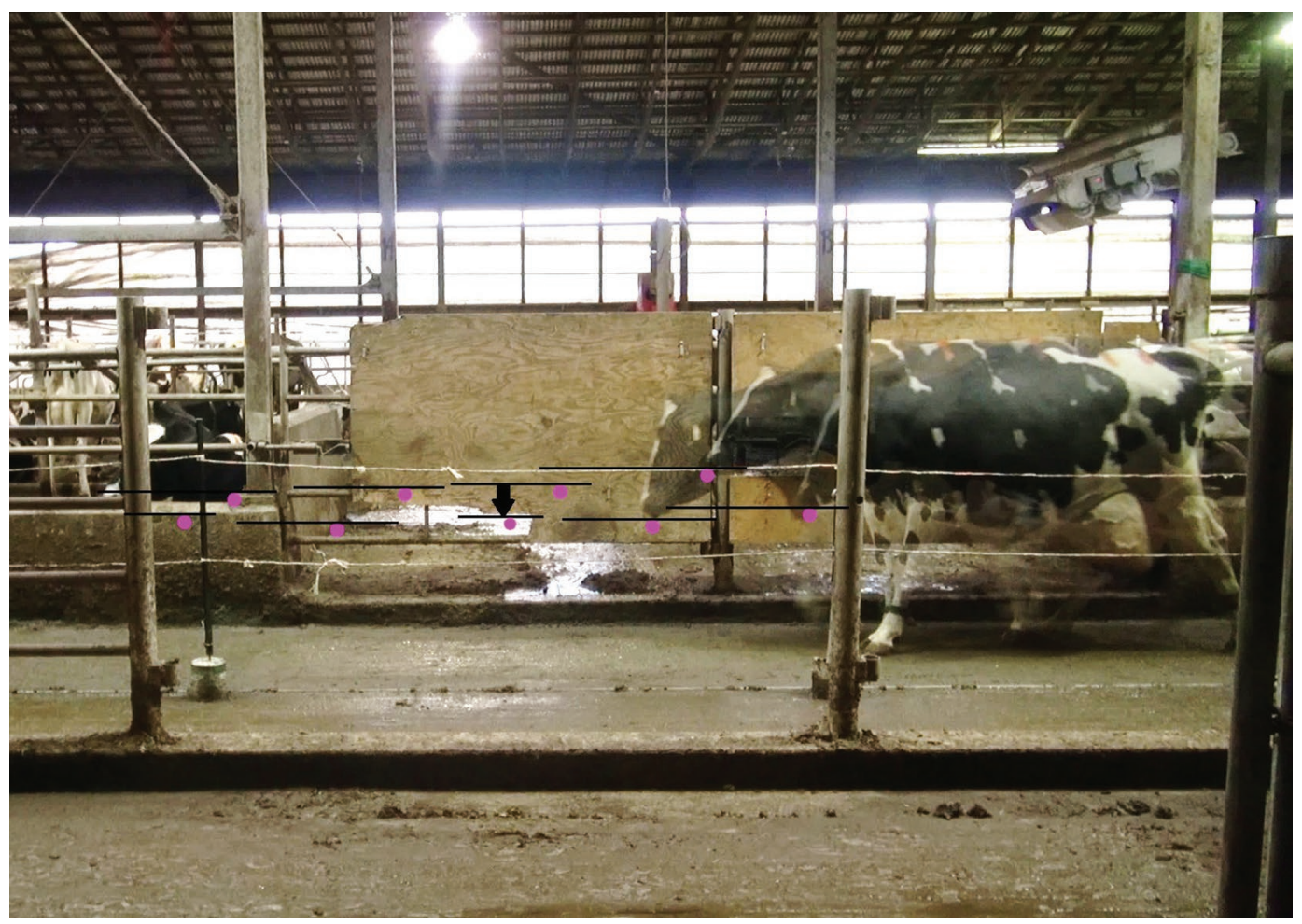

Figure A3. The highest and lowest positions of the lower jaw were marked using Photoshop (Adobe Photoshop CS6, Adobe Systems, San Jose, CA); the arrow shows the vertical distance between 2 successive head positions. 